\title{
The role of plant roots in the Critical Zone and its research framework Teng MA ${ }^{1,2^{*}}$ Haotian $\mathrm{YU}^{1,2}$ Ying JIE ${ }^{1,2}$ Xiaoling $\mathrm{YUE}^{3}$ Yuetao $\mathrm{MA}^{4}$
}

1 School of Environmental Studies, China University of Geosciences (Wuhan), Wuhan 430074, PRC (mateng@cug.edu.cn)

${ }^{2}$ State Key Laboratory of Biogeology and Environmental Geology, China University of Geosciences (Wuhan), Wuhan 430074, PRC

${ }^{3}$ Office of Science and Technology Development, China University of Geosciences (Wuhan), Wuhan 430074, PRC

${ }^{4}$ School of Materials Science and Engineering, Southwest Jiaotong University, Chengdu 610031, PRC

The root is one important organ of a plant. The global plant biomass is about 450 billion tons, and the root biomass accounts for about $25 \%-30 \%$ of the dry weight of the plant biomass. At the global average, the root depth of the desert vegetation reaches 13.4 meters; the taproot of shrubs can even reach tens of meters; the maximum depth of the root of temperate forests and grassland is 3.7 meters and 2.4 meters.

The root of the plant is the link between the terrestrial plant ecosystem and the soil-groundwater system. In order to maintain the growth of the plant and promote the circulation of water, matter and energy in Critical Zone, the root anchors the plant into the soil and absorbs groundwater and nutrients. The absorbed water of crops is about 200-1000 times its dry weight. The transpired water of plant is about $60,000 \mathrm{~km}^{3} /$ year, accounting for about $80 \%-90 \%$ of the continent evaporation. The N, P, S, Si absorbed through plant roots are about 1.35-22.5 billion, 1.8-6.75 billion, 450 million, and 4.5-18 billion tons, respectively.

In addition, the well-developed roots affect the pore structure and material cycle of the soil-groundwater system. The geotropism, hydrotropism and tropism of the plant root makes it penetrate into the pore of soil, as a result of which the pore structure of soil is changed and rock weathering is strengthened. Plants provide carbon to the soil-groundwater system through respiration from the root system, and carbon provided by plants through respiration is about $450-750 \mathrm{Pg}$. The organic matter of root exudates can account for $5-10 \%$ of the net assimilation of plant carbon, mainly including various carbohydrates, vitamins, toxins, etc.

The following studies are recommended:

1. Investigation of the biogeochemical structure of the Critical Zone, establishing the biogeochemical structure of the Critical Zone in different temporal and spatial scales;

2. Monitoring of biogeochemical processes in the Critical Zone, focusing on the cycling process and flux of biogenic elements such as $\mathrm{C}, \mathrm{N}, \mathrm{S}, \mathrm{P}$, and $\mathrm{Si}$;

3. Simulation of the evolution of terrestrial plant ecosystems, establishing an ecological model of the Critical Zone to predict the evolution trend of terrestrial plant ecosystems and propose an artificial planting optimization plan.

Key words: Critical Zone; plant root; biogeochemistry 